Article

\title{
The Influence of O/S Exchange on the Biocatalytical Activity of Benzisoselenazol-3(2H)-ones
}

\author{
Magdalena Obieziurska ${ }^{1}$, Agata J. Pacuła ${ }^{1}$, Ulana Juhas ${ }^{2,3}{ }^{\circledR}$, Jędrzej Antosiewicz ${ }^{2}$ and \\ Jacek Ścianowski ${ }^{1, *(1)}$ \\ 1 Department of Organic Chemistry, Faculty of Chemistry, Nicolaus Copernicus University, 7 Gagarin Street, \\ 87-100 Torun, Poland; magdao@umk.pl (M.O.); pacula@umk.pl (A.J.P.) \\ 2 Department of Bioenergetics and Physiology of Exercise, Medical University of Gdansk, 1 Debinki Street, \\ 80-211 Gdansk, Poland; ulana.juhas@gumed.edu.pl (U.J.); jedrzej.antosiewicz@gumed.edu.pl (J.A.) \\ 3 Department of Immunology, Medical University of Gdansk, 1 Debinki Street, 80-211 Gdansk, Poland \\ * Correspondence: jsch@chem.umk.pl; Tel.: +48-56-611-4532
}

Received: 8 October 2018; Accepted: 22 October 2018; Published: 25 October 2018

check for updates

\begin{abstract}
The crucial feature of organoselenium compounds, when considering them as promising drug candidates in cancer therapy, is their unique ability to alter the cellular redox regulations. Organic Se-molecules continue to demonstrate a positive therapeutic effect both in cancer prevention-as antioxidants, and treatment-as prooxidants. The growing interest in this field of research highlights the need to search for particular pharmacophore motifs, which could enhance the efficiency and selectivity, and decrease the toxicity of potential anticancer agents. Herein, a series of redox-active organoselenium derivatives $-N$-functionalized benzisoselenazol-3(2H)-thiones, has been designed and synthetized. A new synthetic pathway, with the application of Lawesson's reagent, has been developed and efficiently applied. The key steps involving microwave irradiation facilitated performing the reaction in solvent-free conditions, shortening the reaction time and significantly improving the overall yield of the process. Six $N$-alkyl derivatives have been obtained and tested as antioxidant catalysts and anti-proliferative agents. The $\mathrm{N}$-propyl benzisoselenazol-3(2H)-thione was the best peroxide scavenger and the $N$-cyclohexyl derivative exhibited the best cytotoxic activity towards prostate cancer cell line DU145.
\end{abstract}

Keywords: selenium; benzisoselenazol-3(2H)-thiones; redox catalysis; antioxidants; antiproliferative activity

\section{Introduction}

Preservation of redox homeostasis, provided by powerful enzymatic and nonenzymatic antioxidant systems, is essential for cell viability and proper organ function. Environmental factors, UV light, air pollution and failure of the cellular antioxidant defense tools can induce redox imbalance, trigger subsequent overproduction of reactive oxygen species (ROS) and lead to oxidative stress. As physiological oxidative stress (eustress) is essential for redox regulations and signaling, the overoxidation (distress) can cause cell damage and contribute to various diseases including neurodegeneration, diabetes, hypertension and asthma. However, generation of ROS, in some cases like tissue regeneration and cancer, has a therapeutic influence [1]. Depending on the type of the pathophysiological process and also on the stage of the disease, the ability of molecules to influence the redox regulations, decreasing or increasing oxidative stress, can serve a positive impact. The "two-face" character of Selenium, able to act as an antioxidant and prooxidant, creates a good background to design new redox-active compounds with multifunctional pharmacological potential [2]. 
The unique properties of selenium, facile introduction, transformation and elimination from the structure of various organic species along with further numerous synthetical and biological application routs, build-up a constantly developing field of research [3-7]. Among all redox-active organoselenium molecules, ebselen ( $\mathrm{N}$-phenyl-benzisoselenazol-3(2H)-one) is still the only organoselenide admitted to clinical trial. Its mechanism of action is associated with the ability to mimic the catalytical activity of glutathione peroxidase (GPx), a selenoenzyme that protects from oxidative damage [8-11]. Ebselen 1 can directly reduce $\mathrm{H}_{2} \mathrm{O}_{2}$ after transformation to the corresponding selenol 3 [12,13] (Scheme 1).

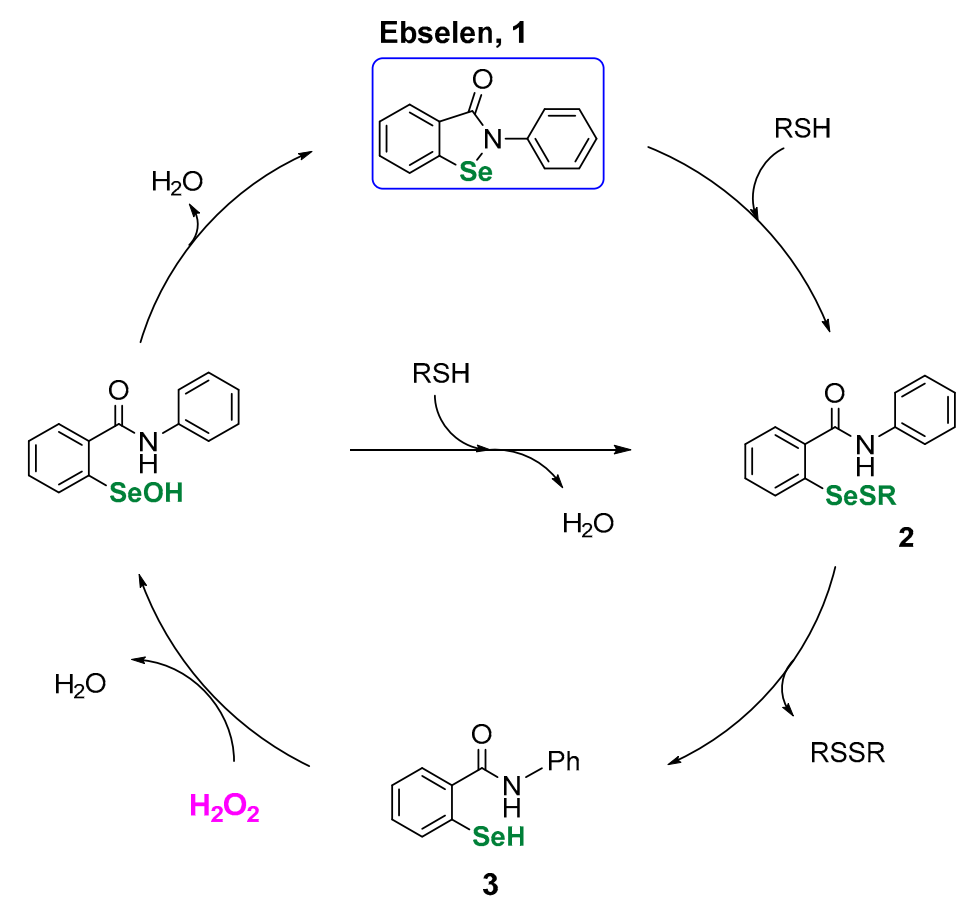

Scheme 1. Mechanism of peroxide reduction by ebselen.

According to the most probable cycle of action, the essential step is the ability of compound $\mathbf{1}$ to form a Se-S bond in compound 2 with glutathione or other endogenous thiols. This way the molecule can act as an enzyme inhibitor, forming a seleno-sulfide conjugation with a cysteine residue, and thus providing other interesting pharmacological properties. Additionally, in higher concentrations, it can be used as a prooxidant and induce apoptosis of cancer cells [14].

To increase the activity and selectivity of ebselen, various modifications of its structure were efficiently conducted by several research groups. Promising results exposed the significant potential in this field of organoselenium chemistry [15-19]. However, there are only few examples of derivatives bearing a sulfur atom in the place of oxygen [20]. Until now, the influence of the thiocarbonyl group on the biological activity of benzisoselenazolones has not been thoroughly evaluated. Designing a new efficient method for the synthesis of benzisoselenazolthiones would make this group of organoselenium derivatives more accessible and as a consequence enable us to thoroughly investigate the influence of this modification on the activity of benzisoselenazolones. We assumed that the exchange of the carbonyl to thiocarbonyl group, leading to the decrease of the polarity of the double bond, could influence the stability of the Se-N bond and the speed of the formation of S-Se bond.

\section{Results and Discussion}

All obtained derivatives are a combination of 3 structural motifs: (1) the ebselen core, essential for the GPx-like activity, ability to catalytically eliminate reactive oxygen species and influence the physiological function of proteins by forming a seleno-sulfide bond with their thiol groups; (2) a thioamide moiety, similar to the thiourea structure, an important pharmacophore in medicinal 
chemistry, broadly incorporated in the structure of various drugs e.g., anti-cancer, anti-bacterial and anti-viral [21]; (3) and an $\mathrm{N}$-alkyl substituent that could potentially enhance the solubility of the compounds and influence the interaction of benzisoselenazolthiones with different cell structures (Scheme 2).

\section{thioamide moiety}

change in the reactivity of the Se-N bond

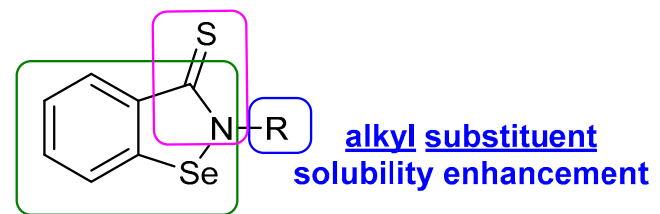

GPx- mimic

antioxidant and anticancer activity

Scheme 2. General structure of the designed molecules.

Previously, we had observed that the stability of the Se-N bond influences the reactivity of benzisoselenazolones. Derivatives that could be easily transformed to diselenides were the most efficient antioxidants. In contrast, compounds possessing a stable Se-N bond were weak peroxide scavengers but good anticancer agents [22]. The exchange of the carbonyl to thiocarbony group, presented in this paper, could influence the strength of the Se-N bond and the reactivity of the synthetized compounds. Additionally, the selection of different $N$-alkyl substituents, short, long and more sterically hindered carbon chains can enable us to choose the best chain length for achieving the highest biological activity.

\subsection{Chemistry}

The main synthetical goal of the study was to develop an efficient procedure, using the commonly applied Lawesson's reagent [23] for the introduction of the sulfur atom in the structure of $N$-alkylbenzisoselenazolones. We have planned to obtain $N$-alkylbenzisoselenazolthiones by different two-step procedures: (Method A) involving the reaction of $\mathrm{N}$-alkyl-o-iodobenzamides 4 with Lawesson's reagent to obtain corresponding thioamides 5, followed by nucleophilic substitution with $\mathrm{Li}_{2} \mathrm{Se}_{2}$ leading to the final Se-N bond formation, and (Method $\mathbf{B}$ ) also starting from $\mathrm{N}$-alkyl-o-iodobenzamides 4 , their next reaction with $\mathrm{Li}_{2} \mathrm{Se}_{2}$ to obtain benzisoselenazolones $\mathbf{6}$, which are then directly converted to their sulfur analogues 7 (Scheme 3).

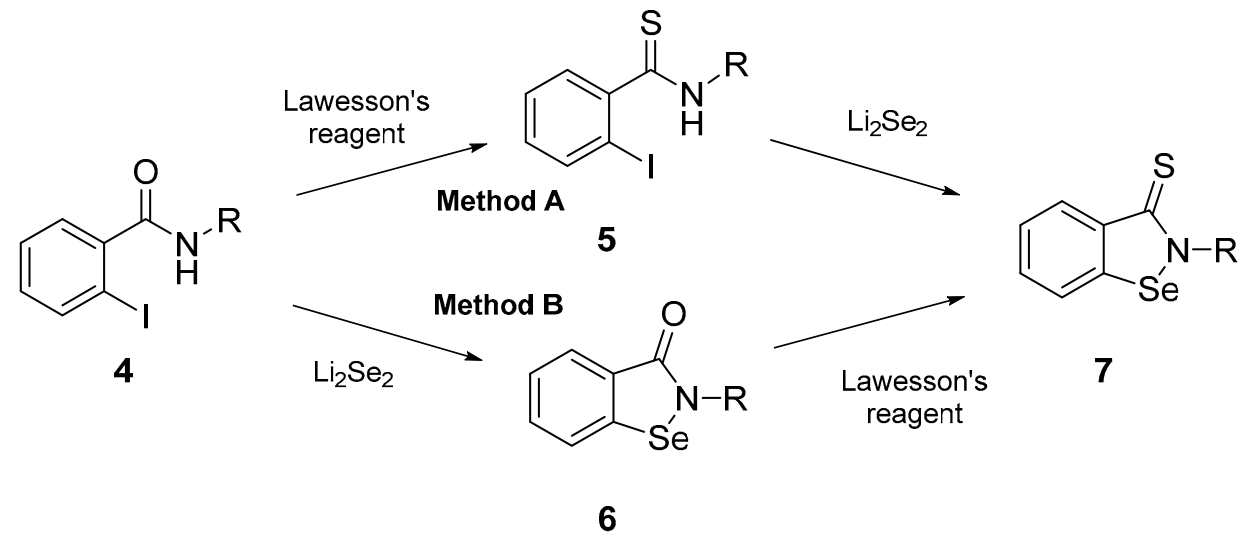

Scheme 3. Methods A and B used to obtain thio-derivatives 7.

The first step included the synthesis of carbonyl substrates for the transformation of oxygen-based functional groups to their thio-analogues. Using our previously designed procedures we have obtained 
a series of $\mathrm{N}$-alky-o-iodobenzamides $4 \mathbf{a}-\mathbf{f}$ that were further transformed, by the reaction with dilithium diselenide, into corresponding $N$-alkylbenzisoselenazolones 6a-f $[24,25]$ (Scheme 4).

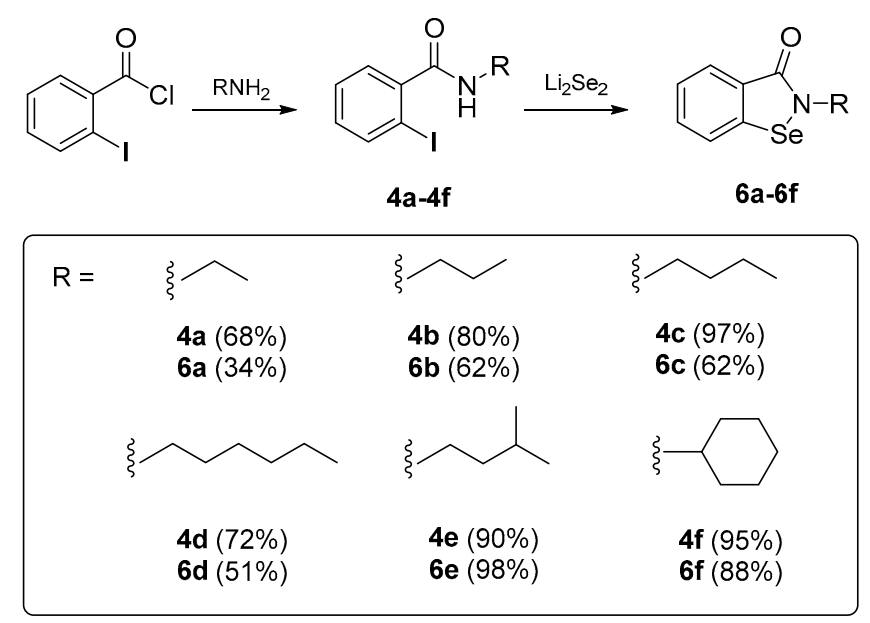

Scheme 4. Synthesis of carbonyl substrates.

The treatment of amides 4a-f with Lawessons's reagent (LR) carried out in standard conditions [26] (Method C) resulted in only moderate yields of the thioamides 5a-f. Performing the reaction with microwave irradiation in solvent-free conditions (Method D) enabled us to significantly reduce the reaction time $(3 \mathrm{~min})$ and obtain the final product in good yield (44-81\%) (Table 1).

Table 1. Thioamide synthesis-Method C and D.

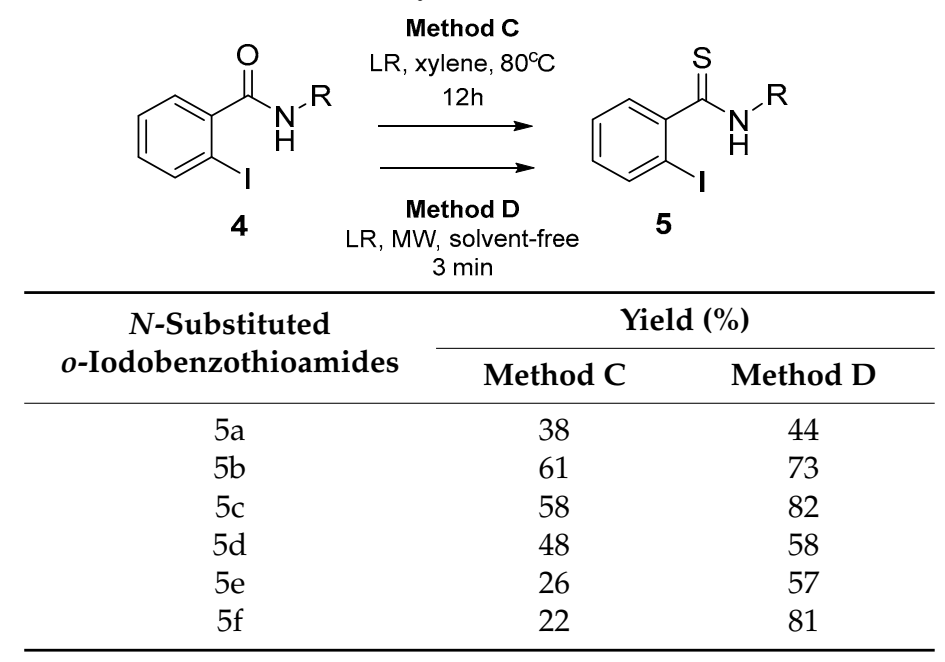

Obtained thioamides $\mathbf{5 a}-\mathbf{f}$ were further transformed to benzisoselenazolthiones $\mathbf{7 a}-\mathbf{f}$, by the procedure using dilithium diselenide (Method E) [24]. The same series of sulfur derivatives $7 \mathbf{a}-\mathbf{f}$ was synthetized by the reaction of previously obtained benzisoselenazolones $\mathbf{5 a}-\mathbf{f}$ with Lawesson's reagent (Method $\mathbf{F}$ ). In contrast to method $\mathbf{D}$, the reaction could not be performed under microwave irradiation. Decomposition of the substrate was observed and only traces of the product were isolated. High temperature and longer reaction time needed to be applied giving low to moderate reaction yields. The results of methods $\mathbf{E}$ and $\mathbf{F}$, and overall yields of both two-step procedures $\mathbf{A}$ and $\mathbf{B}$ are presented in Scheme 5. 

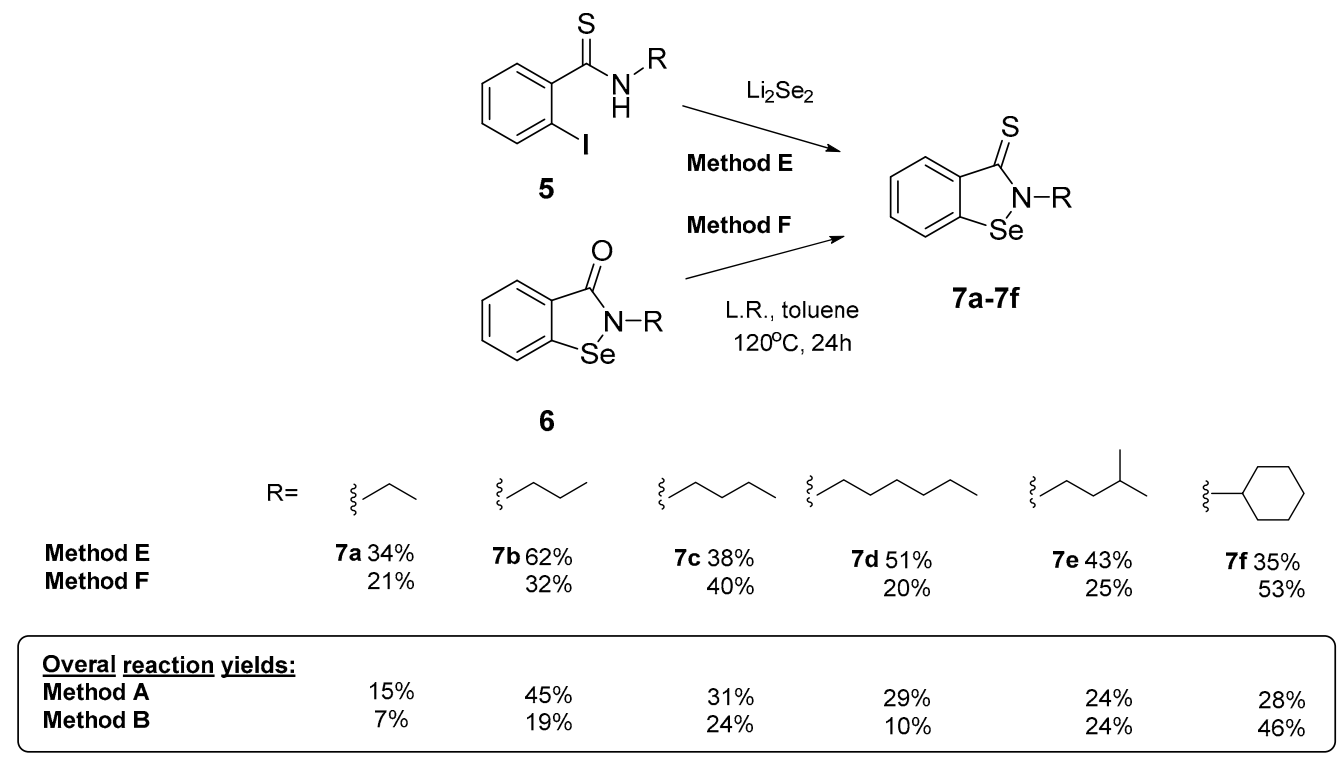

Scheme 5. Synthesis of $N$-alkylbenzselenazolthiones.

For all compounds besides the $N$-cyclohexyl derivative $\mathbf{7 f}$, method A was more efficient. The newly developed procedure involving microwave irradiation improved the methodology by shortening the time and increasing the yield of the reaction.

\subsection{Catalytical and Biological Activity Evaluation}

The final goal of the project was to evaluate the catalytical and biological potential of benzisoselenazolthiones $\mathbf{7 a}-\mathbf{f}$. First, all derivatives were tested as antioxidants using a conventionally applied nuclear magnetic resonance spectroscopy (NMR) assay proposed by Iwaoka and co-workers [27]. The efficiency of the hydroperoxide reduction by the Se-catalyst was equal to the rate of oxidation of DTT ${ }^{\text {red }}$ to DTT ${ }^{\text {ox }}$. The amount of the unreacted dithiol DTT ${ }^{\text {red }}$ was measured by ${ }^{1} \mathrm{H}$ NMR spectra in specific time intervals. The results for both carbonyl $\mathbf{6 a}-\mathbf{f}$ and thiocarbonyl $\mathbf{7 a}-\mathbf{f}$ derivatives are collected in Table 2.

The highest reactivity was observed for the $N$-propyl $7 \mathbf{b}$ and $N$-3-methylbuthyl benzisoselenazolthione 7e. After $1 \mathrm{~h}$ for compound $7 \mathrm{e}$ the amount of the remaining dithiol was only $15 \%$ and in case of derivative $7 \mathbf{b}$ no substrate was present in the reaction mixture. Similar results were collected for corresponding oxo-derivatives $\mathbf{6 b}$ and $\mathbf{6 e}$. In case of $N$-propyl benzisoselenazolthione $7 \mathrm{~b}$ and benzisoselenazolone $\mathbf{6 b}$ the presence of sulfur atom instead of oxygen significantly increased the antioxidant potential. Interestingly, the high activity of compound $7 \mathrm{e}$ fits to our previously observed trend that derivatives possessing a 3-methylbuthyl carbon chain in their structure, like $N$-3-methylbuthylbenzisoselenazolone 6e [22] and $N$-leucine methyl ester derivative 8 [28], exhibit significantly better antioxidant potential than ebselen (Figure 1).

It can be concluded, that the presence of $N$-propyl and 3-methylbuthyl carbon chain in the structure of $\mathrm{N}$-alkyl benzisoselenazolones and benzisoselenazolthiones improves the peroxide scavenging properties. We can assume that the selected carbon chains provide an optimal combination of steric effect, Se-N bond stability and solubility enhancement.

Next, cytotoxic activity of the obtained derivatives was evaluated by the SRB viability assay on prostate cancer cell line DU-145 and also on non-cancerous cell line PNT1A. The IC 50 values for the tested benzisoselenazolthiones $\mathbf{7 a}-\mathbf{f}$, in comparison to the activity of the corresponding oxo-analogues 6a-f are presented in Table 3. 
Table 2. Results of the antioxidant activity assay.

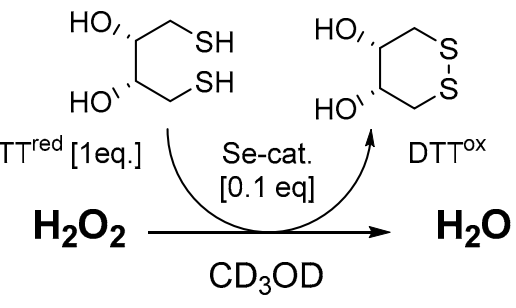

\begin{tabular}{cccccc}
\hline & \multicolumn{5}{c}{ Remaining Dithiotreitol (\%) } \\
\hline Catalyst [0.1 equiv.] & $3 \mathrm{~min}$ & $5 \mathrm{~min}$ & $15 \mathrm{~min}$ & $30 \mathrm{~min}$ & $60 \mathrm{~min}$ \\
\hline Benzisoselenazolones & & & & & \\
\hline $\mathbf{6 a}$ & 87 & 80 & 65 & 56 & 46 \\
$\mathbf{6 b}$ & 77 & 57 & 38 & 26 & 15 \\
$\mathbf{6 c}$ & 81 & 59 & 41 & 32 & 29 \\
$\mathbf{6 d}$ & 92 & 84 & 81 & 78 & 75 \\
$\mathbf{6 e}$ & 77 & 58 & 42 & 28 & 13 \\
$\mathbf{6 f}$ & 75 & 69 & 62 & 55 & 44 \\
\hline Benzisoselenazolthiones & & & & & \\
\hline 7a & 99 & 97 & 96 & 95 & 93 \\
$\mathbf{7 b}$ & 43 & 21 & 3 & 2 & 0 \\
7c & 97 & 97 & 96 & 96 & 95 \\
7d & 99 & 98 & 98 & 98 & 97 \\
7e & 40 & 26 & 18 & 17 & 15 \\
7f & 90 & 84 & 74 & 65 & 47 \\
\hline Ebselen (1) & 84 & 75 & 64 & 58 & 52 \\
\hline
\end{tabular}

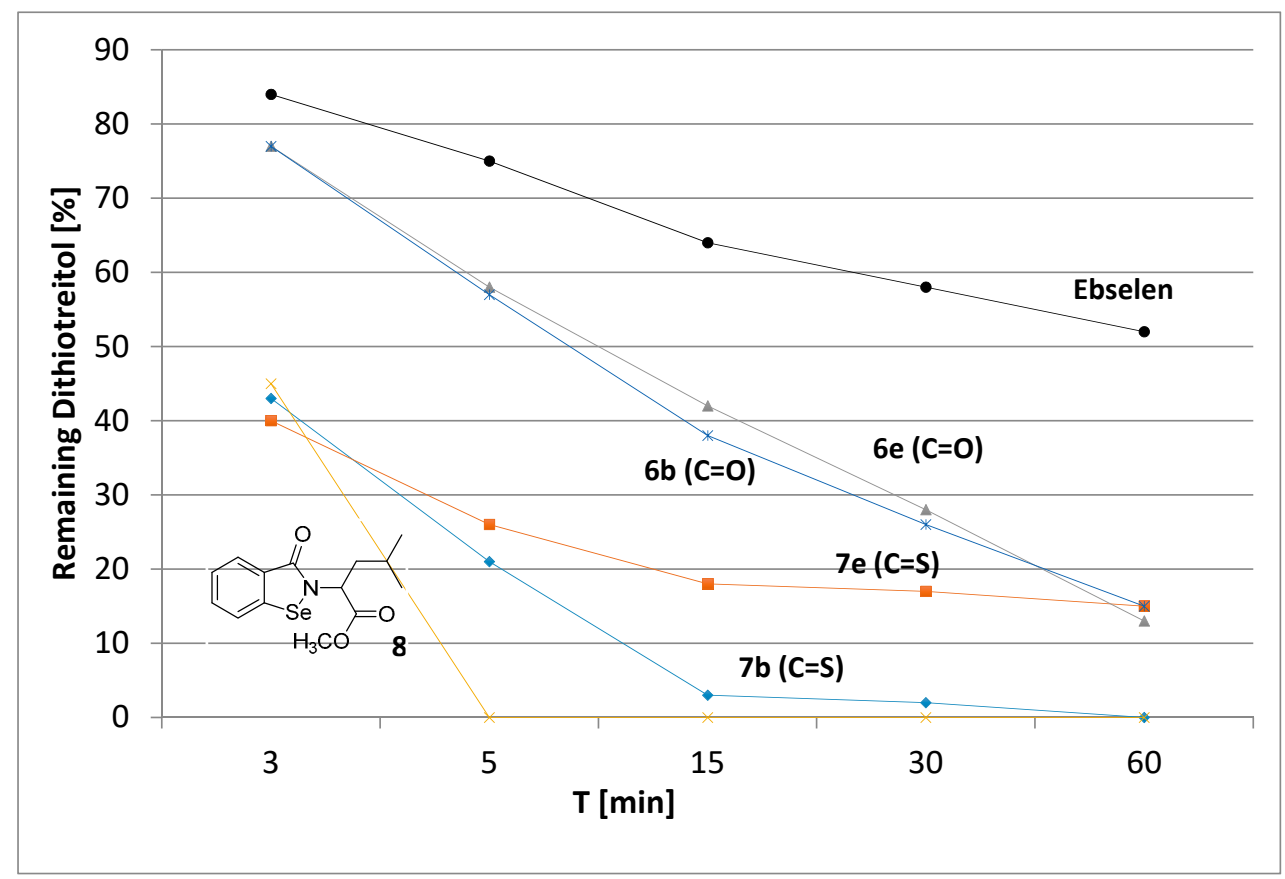

Figure 1. Graphical comparison of antioxidant activities. 
Table 3. Cytotoxic activity evaluated in vitro.

\begin{tabular}{ccc}
\hline Compound & DU-145 & PNT1A \\
\hline \multicolumn{2}{c}{ IC $_{\mathbf{5 0},} \boldsymbol{\mu M}$} \\
\hline 6a & 30.06 & 20.68 \\
6b & 30.21 & $>60$ \\
$\mathbf{6 c}$ & 20.76 & $>40$ \\
$\mathbf{6 e}$ & 30.39 & $>40$ \\
$\mathbf{6 f}$ & 5.71 & $>40$ \\
$\mathbf{7 a}$ & 15.33 & 20.29 \\
$\mathbf{7 b}$ & 20.36 & 20.77 \\
$\mathbf{7 f}$ & 10.7 & 5.63 \\
\hline & $\mathbf{4 0} \boldsymbol{\mu M}($ Cell Viability (\%)) \\
\hline 6d & 51.429 & 95.669 \\
$\mathbf{7 c}$ & 52.161 & 58.060 \\
7d & 56.829 & 65.027 \\
7e & 61.177 & 60.74 \\
\hline
\end{tabular}

The best antiproliferative activity was observed for $N$-cyclohexylbenzisoselenazolthione $\mathbf{7 f}$. The corresponding $N$-cyclohexylbenzisoselenazolon $\mathbf{6 f}$ was also the most efficient cytotoxic agent among the previously tested $\mathrm{N}$-alkyl benzisoselenazolones [22]. However, in contrary to thio-analogue $7 f$, the carbonyl derivative selectively inhibited the proliferation of cancer cell line DU-145 and was not toxic to non-cancerous cell line PNT1A.

\section{Materials and Methods}

\subsection{Chemistry}

\subsubsection{General}

${ }^{1} \mathrm{H}$ NMR spectra were obtained at 400 or $700 \mathrm{MHz}$ and chemical shifts were recorded relative to $\mathrm{SiMe}_{4}(80.00)$ or solvent resonance $\left(\mathrm{CDCl}_{3} \delta 7.26, \mathrm{CD}_{3} \mathrm{OD} \delta 3.31\right)$. Multiplicities were given as: $\mathrm{s}$ (singlet), $d$ (doublet), dd (double doublet), ddd (double double doublet), $t$ (triplet), dt (double triplet) and $\mathrm{m}$ (multiplet). The number of protons (n) for a given resonance was indicated by $\mathrm{nH}$. Coupling constants were reported as a $J$ value in $\mathrm{Hz} .{ }^{13} \mathrm{C}$ NMR spectra were acquired at $100.6 \mathrm{~Hz}$ and chemical shifts were recorded relative to solvent resonance $\left(\mathrm{CDCl}_{3}\right.$ 877.25). NMR spectra were carried out using ACD/NMR Processor Academic Edition (please see the Supplementary Materials). Commercially available solvents DMF, DCM and $\mathrm{MeOH}$ (Sigma Aldrich, St. Louis, MO, USA) and chemicals were used without further purification. Column chromatography was performed using Merck 40-63D $60 \AA$ silica gel (Sigma Aldrich, St. Louis, MO, USA).

\subsubsection{Synthesis of $o$-iodobenzamides $4 \mathrm{a}, 4 \mathrm{~b}$ and $4 \mathrm{~d}$}

$2 \% \mathrm{NaOH}(4.4 \mathrm{~mL})$ was added to a solution of an amine $(1.0 \mathrm{mmol})$ in DCM $(2 \mathrm{~mL})$. The mixture was cooled to $0{ }^{\circ} \mathrm{C}$ and $o$-iodobenzoic acid chloride $(1.1 \mathrm{mmol})$ dissolved in DCM $(3 \mathrm{~mL})$ was added dropwise. The reaction mixture was stirred in room temperature for $20 \mathrm{~h}$ and the product was extracted with DCM. Combined organic layers were washed with saturated $\mathrm{NaHCO}_{3}$ and dried over magnesium sulfate. The solvent was removed under reduced pressure and the product was obtained as white solid. Synthesis and characterization of compounds $\mathbf{4 c}, \mathbf{4 e}$ and $\mathbf{4 f}$ are described in our previous paper [24]

\section{$N$-ethyl-o-iodobenzamide $\mathbf{4 a}$}

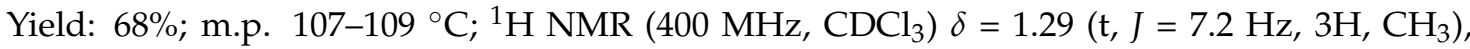
3.48-3.56 (m, 2H, N-CH $), 5.73(\mathrm{bs}, 1 \mathrm{H}, \mathrm{NH}), 7.10\left(\mathrm{ddd}, J=8.0,6.8,2.4 \mathrm{~Hz}, 1 \mathrm{H}, 1 \mathrm{H}_{\mathrm{ar}}\right), 7.36-7.43(\mathrm{~m}, 2 \mathrm{H}$, $\left.2 \mathrm{H}_{\mathrm{ar}}\right), 7.86\left(\mathrm{dd}, J=7.6,0.8 \mathrm{~Hz}, 1 \mathrm{H}, 1 \mathrm{H}_{\mathrm{ar}}\right) \mathrm{ppm} ;{ }^{13} \mathrm{C} \mathrm{NMR}\left(100.6 \mathrm{MHz}, \mathrm{CDCl}_{3}\right) \delta=14.68\left(\mathrm{CH}_{3}\right), 35.01$ 
$\left(\mathrm{CH}_{2}-\mathrm{N}\right), 92.42\left(\mathrm{C}_{\mathrm{ar}}\right), 128.16\left(\mathrm{CH}_{\mathrm{ar}}\right), 128.24\left(\mathrm{CH}_{\mathrm{ar}}\right), 131.00\left(\mathrm{CH}_{\mathrm{ar}}\right), 139.80\left(\mathrm{CH}_{\mathrm{ar}}\right), 142.47\left(\mathrm{C}_{\mathrm{ar}}\right), 169.26$ $(\mathrm{C}=\mathrm{O}) \mathrm{ppm}[29]$.

$\mathrm{N}$-propyl-o-iodobenzamide $\mathbf{4 b}$

Yield: $80 \%$; m.p. ${ }^{105-107}{ }^{\circ} \mathrm{C}$; ${ }^{1} \mathrm{H}$ NMR $\left(400 \mathrm{MHz}, \mathrm{CDCl}_{3}\right) \delta=1.04\left(\mathrm{t}, J=7.2 \mathrm{~Hz}, 3 \mathrm{H}, \mathrm{CH}_{3}\right)$, 1.66-1.73 (m, 2H, $\left.\mathrm{CH}_{2}\right), 3.42-3.47\left(\mathrm{~m}, 2 \mathrm{H}, \mathrm{N}-\mathrm{CH}_{2}\right), 5.78$ (bs, $\left.1 \mathrm{H}, \mathrm{NH}\right), 7.10$ (ddd, $J=8.0,6.8,2.4 \mathrm{~Hz}, 1 \mathrm{H}$, $\left.1 \mathrm{H}_{\mathrm{ar}}\right), 7.36-7.42\left(\mathrm{~m}, 2 \mathrm{H}, 2 \mathrm{H}_{\mathrm{ar}}\right), 7.87\left(\mathrm{dd}, J=7.6,0.8 \mathrm{~Hz}, 1 \mathrm{H}, 1 \mathrm{H}_{\mathrm{ar}}\right) \mathrm{ppm} ;{ }^{13} \mathrm{C} \mathrm{NMR}\left(100.6 \mathrm{MHz}, \mathrm{CDCl}_{3}\right)$ $\delta=11.53\left(\mathrm{CH}_{3}\right), 22.72\left(\mathrm{CH}_{2}\right), 41.83\left(\mathrm{CH}_{2}-\mathrm{N}\right), 92.38\left(\mathrm{C}_{\mathrm{ar}}\right), 128.16\left(\mathrm{CH}_{\mathrm{ar}}\right), 128.27\left(\mathrm{CH}_{\mathrm{ar}}\right), 131.00\left(\mathrm{CH}_{\mathrm{ar}}\right)$, $139.83\left(\mathrm{CH}_{\mathrm{ar}}\right), 142.60\left(\mathrm{C}_{\mathrm{ar}}\right), 169.37(\mathrm{C}=\mathrm{S}) \mathrm{ppm}[30]$.

$\mathrm{N}$-hexyl-o-iodobenzamide $4 \mathbf{d}$

Yield: $72 \%$; m.p. $98-100{ }^{\circ} \mathrm{C} ;{ }^{1} \mathrm{H}$ NMR $\left(700 \mathrm{MHz}, \mathrm{CDCl}_{3}\right) \delta=0.93\left(\mathrm{t}, J=7.0 \mathrm{~Hz}, 3 \mathrm{H}, \mathrm{CH}_{3}\right), 1.30-1.35$ $\left(\mathrm{m}, 4 \mathrm{H}, 2 \mathrm{CCH}_{2}\right), 1.39-1.43\left(\mathrm{~m}, 2 \mathrm{H}, \mathrm{CH}_{2}\right), 1.61-1.65\left(\mathrm{~m}, 2 \mathrm{H}, \mathrm{CH}_{2}\right), 3.43-3.46\left(\mathrm{~m}, 2 \mathrm{H}, \mathrm{N}-\mathrm{CH}_{2}\right), 5.73$ (bs, $1 \mathrm{H}, \mathrm{NH}), 7.10\left(\mathrm{ddd}, J=7.7,7.0,2.1 \mathrm{~Hz}, 1 \mathrm{H}, 1 \mathrm{H}_{\mathrm{ar}}\right), 7.35-7.40\left(\mathrm{~m}, 2 \mathrm{H}, 2 \mathrm{H}_{\mathrm{ar}}\right), 7.85(\mathrm{dd}, J=7.7,0.7 \mathrm{~Hz}, 1 \mathrm{H}$, $\left.1 \mathrm{H}_{\mathrm{ar}}\right) \mathrm{ppm} ;{ }^{13} \mathrm{C} \mathrm{NMR}\left(100.6 \mathrm{MHz}, \mathrm{CDCl}_{3}\right) \delta=14.03\left(\mathrm{CH}_{3}\right), 22.57\left(\mathrm{CH}_{2}\right), 26.68\left(\mathrm{CH}_{2}\right), 29.36\left(\mathrm{CH}_{2}\right), 31.47$ $\left(\mathrm{CH}_{2}\right), 40.13\left(\mathrm{CH}_{2}-\mathrm{N}\right), 92.44\left(\mathrm{C}_{\mathrm{ar}}\right), 128.12\left(\mathrm{CH}_{\mathrm{ar}}\right), 128.25\left(\mathrm{CH}_{\mathrm{ar}}\right), 130.93\left(\mathrm{CH}_{\mathrm{ar}}\right), 139.78\left(\mathrm{CH}_{\mathrm{ar}}\right), 142.58$ $\left(\mathrm{C}_{\text {ar }}\right), 169.32(\mathrm{C}=\mathrm{O}) \mathrm{ppm}[31]$.

\subsubsection{Synthesis of $o$-iodobenzthioamides $\mathbf{5 a}-\mathbf{5 f}$}

Method C: To a solution of amide $(1.0 \mathrm{mmol})$ in xylene $(10 \mathrm{~mL})$ Lawesson's reagent $(0.70 \mathrm{mmol})$ was added portionwise and the mixture was stirred overnight at $80^{\circ} \mathrm{C}$. Solvent was removed under vacuum and the resulting crude product was purified by silica gel column chromatography (solvent: Dichloromethane).

Method D: Amide $(1.0 \mathrm{mmol})$ and Lawesson's reagent $(0.70 \mathrm{mmol})$ was manually mixed in a biker and placed in a household microwave oven for $3 \mathrm{~min}(700 \mathrm{~W})$. The crude product was dissolved in dichloromethane, directly placed on silica and purified by silica gel column chromatography (solvent: Dichloromethane).

\section{N-ethyl-o-iodobenzthioamide 5a}

Yield: $38,44 \%$; m.p. $155-157{ }^{\circ} \mathrm{C} ;{ }^{1} \mathrm{H}$ NMR $\left(400 \mathrm{MHz}, \mathrm{CDCl}_{3}\right) \delta=1.41\left(\mathrm{t}, J=7.6 \mathrm{~Hz}, 3 \mathrm{H}, \mathrm{CH}_{3}\right)$, $3.83-3.90\left(\mathrm{~m}, 2 \mathrm{H}, \mathrm{N}-\mathrm{CH}_{2}\right), 7.05\left(\mathrm{ddd}, J=8.0,8.0,1.6 \mathrm{~Hz}, 1 \mathrm{H}, 1 \mathrm{H}_{\mathrm{ar}}\right), 7.25(\mathrm{bs}, 1 \mathrm{H}, \mathrm{NH}), 7.37(\mathrm{dt}, J=7.6$, $\left.1.2 \mathrm{~Hz}, 1 \mathrm{H}, 1 \mathrm{H}_{\mathrm{ar}}\right), 7.45\left(\mathrm{dd}, J=7.6,1.2 \mathrm{~Hz}, 1 \mathrm{H}, 1 \mathrm{H}_{\mathrm{ar}}\right), 7.83\left(\mathrm{dd}, J=8.0,1.2 \mathrm{~Hz}, 1 \mathrm{H}, 1 \mathrm{H}_{\mathrm{ar}}\right) \mathrm{ppm} ;{ }^{13} \mathrm{C} \mathrm{NMR}$ $\left(100.6 \mathrm{MHz}, \mathrm{CDCl}_{3}\right) \delta=12.97\left(\mathrm{CH}_{3}\right), 41.21\left(\mathrm{CH}_{2}-\mathrm{N}\right), 92.04\left(\mathrm{C}_{\mathrm{ar}}\right), 128.25\left(\mathrm{CH}_{\mathrm{ar}}\right), 128.35\left(\mathrm{CH}_{\mathrm{ar}}\right), 130.24$ $\left(\mathrm{CH}_{\mathrm{ar}}\right), 139.60\left(\mathrm{CH}_{\mathrm{ar}}\right), 148.29\left(\mathrm{C}_{\mathrm{ar}}\right), 200.88$ (C=S); IR: 3158, 3042, 2973, 2930, 1548, 1449, 1398, 1336, 1298, 1259, 1231, 1053, $1017 \mathrm{~cm}^{-1}$. Elemental Anal. Calcd for $\mathrm{C}_{9} \mathrm{H}_{10} \mathrm{INS}$ (291.15): C, 37.13; H, 3.46. Found: $\mathrm{C}$, $37.02 ; \mathrm{H}, 3.41$.

\section{$N$-propyl-o-iodobenzthioamide $\mathbf{5 b}$}

Yield: $61,73 \%$; m.p. $128-130{ }^{\circ} \mathrm{C} ;{ }^{1} \mathrm{H}$ NMR $\left(400 \mathrm{MHz}, \mathrm{CDCl}_{3}\right) \delta=1.09\left(\mathrm{t}, J=7.2 \mathrm{~Hz}, 3 \mathrm{H}, \mathrm{CH}_{3}\right)$, 1.79-1.88 (m, 2H, CH $)_{2}, 3.77-3.82\left(\mathrm{~m}, 2 \mathrm{H}, \mathrm{N}-\mathrm{CH}_{2}\right), 7.05\left(\mathrm{ddd}, J=8.0,7.6,2.0 \mathrm{~Hz}, 1 \mathrm{H}, 1 \mathrm{H}_{\mathrm{ar}}\right), 7.25(\mathrm{bs}, 1 \mathrm{H}$, $\mathrm{NH}), 7.37\left(\mathrm{dt}, J=7.6,1.2 \mathrm{~Hz}, 1 \mathrm{H}, 1 \mathrm{H}_{\mathrm{ar}}\right), 7.45\left(\mathrm{dd}, J=7.6,1.6 \mathrm{~Hz}, 1 \mathrm{H}, 1 \mathrm{H}_{\mathrm{ar}}\right), 7.83(\mathrm{dd}, J=8.4,1.2 \mathrm{~Hz}$, $\left.1 \mathrm{H}, 1 \mathrm{H}_{\mathrm{ar}}\right) \mathrm{ppm} ;{ }^{13} \mathrm{C}$ NMR $\left(100.6 \mathrm{MHz}, \mathrm{CDCl}_{3}\right) \delta=11.73\left(\mathrm{CH}_{3}\right), 21.20\left(\mathrm{CH}_{2}\right), 48.04\left(\mathrm{CH}_{2}-\mathrm{N}\right), 91.92\left(\mathrm{C}_{\mathrm{ar}}\right)$, $128.27\left(\mathrm{CH}_{\mathrm{ar}}\right), 128.35\left(\mathrm{CH}_{\mathrm{ar}}\right), 130.22\left(\mathrm{CH}_{\mathrm{ar}}\right), 139.63\left(\mathrm{CH}_{\mathrm{ar}}\right), 148.48\left(\mathrm{C}_{\mathrm{ar}}\right), 201.19(\mathrm{C}=\mathrm{S}) ; \mathrm{IR}: 3151,3025$, 2987, 2963, 2926, 2869, 1538, 1454, 1441, 1429, 1413, 1394, 1372, 1353, 1296, 1282, 1252, 1224, 1179, 1153, $1115,1059,1034,1011 \mathrm{~cm}^{-1}$. Elemental Anal. Calcd for $\mathrm{C}_{10} \mathrm{H}_{12} \mathrm{INS}$ (305.177): C, 39.36; H, 3.96. Found: C, 39.45; H, 3.92 . 
$\mathrm{N}$-butyl-o-iodobenzthioamide $\mathbf{5 c}$

Yield: $58,62 \%$; m.p. $73-75{ }^{\circ} \mathrm{C} ;{ }^{1} \mathrm{H}$ NMR $\left(700 \mathrm{MHz}, \mathrm{CDCl}_{3}\right) \delta=1.02\left(\mathrm{t}, J=7.7 \mathrm{~Hz}, 3 \mathrm{H}, \mathrm{CH}_{3}\right)$, 1.50-1.54 (m, 2H, $\left.\mathrm{CH}_{2}\right), 1.77-1.81\left(\mathrm{~m}, 2 \mathrm{H}, \mathrm{CH}_{2}\right), 3.82-3.85\left(\mathrm{~m}, 2 \mathrm{H}, \mathrm{N}-\mathrm{CH}_{2}\right), 7.06(\mathrm{ddd}, J=8.4,7.0,1.4$ $\left.\mathrm{Hz}, 1 \mathrm{H}, 1 \mathrm{H}_{\mathrm{ar}}\right), 7.28(\mathrm{bs}, 1 \mathrm{H}, \mathrm{NH}), 7.39\left(\mathrm{ddd}, J=7.7,7.0,1.4 \mathrm{~Hz}, 1 \mathrm{H}, 1 \mathrm{H}_{\mathrm{ar}}\right), 7.45(\mathrm{dd}, J=7.7,1.4 \mathrm{~Hz}$, $\left.1 \mathrm{H}, 1 \mathrm{H}_{\mathrm{ar}}\right), 7.84\left(\mathrm{dd}, J=8.4,1.4 \mathrm{~Hz}, 1 \mathrm{H}, 1 \mathrm{H}_{\mathrm{ar}}\right) \mathrm{ppm} ;{ }^{13} \mathrm{C} \mathrm{NMR}\left(100.6 \mathrm{MHz}, \mathrm{CDCl}_{3}\right) \delta=13.76\left(\mathrm{CH}_{3}\right)$, $20.38\left(\mathrm{CH}_{2}\right), 29.85\left(\mathrm{CH}_{2}\right), 46.10\left(\mathrm{CH}_{2}-\mathrm{N}\right), 91.96\left(\mathrm{C}_{\mathrm{ar}}\right), 128.26\left(\mathrm{CH}_{\mathrm{ar}}\right), 128.35\left(\mathrm{CH}_{\mathrm{ar}}\right), 130.20\left(\mathrm{CH}_{\mathrm{ar}}\right), 139.62$ $\left(\mathrm{CH}_{\mathrm{ar}}\right), 148.45\left(\mathrm{C}_{\mathrm{ar}}\right), 201.05$ (C=S); IR: 3158, 3029, 2989, 2961, 2927, 2869, 1540, 1455, 1428, 1392, 1354, $1339,1303,1280,1261,1217,1154,1115,1060,1044,1013 \mathrm{~cm}^{-1}$. Elemental Anal. Calcd for $\mathrm{C}_{11} \mathrm{H}_{14} \mathrm{INS}$ (319.204): C, 41.39; H, 4.42. Found: C, 41.34; H, 4.49.

\section{N-hexyl-o-iodobenzthioamide $\mathbf{5 d}$}

Yield: 48, 58\%; yellow oil; ${ }^{1} \mathrm{H}$ NMR $\left(400 \mathrm{MHz}, \mathrm{CDCl}_{3}\right) \delta=0.93\left(\mathrm{t}, J=7.2 \mathrm{~Hz}, 3 \mathrm{H}, \mathrm{CH}_{3}\right), 1.35-1.37$ $\left(\mathrm{m}, 4 \mathrm{H}, 2 \mathrm{CCH}_{2}\right), 1.44-1.51\left(\mathrm{~m}, 2 \mathrm{H}, \mathrm{CH}_{2}\right), 1.76-1.83\left(\mathrm{~m}, 2 \mathrm{H}, \mathrm{CH}_{2}\right), 3.79-3.84\left(\mathrm{~m}, 2 \mathrm{H}, \mathrm{N}_{-} \mathrm{CH}_{2}\right), 7.04$ (ddd, $\left.J=9.2,7.6,2.0 \mathrm{~Hz}, 1 \mathrm{H}, 1 \mathrm{H}_{\mathrm{ar}}\right), 7.25(\mathrm{bs}, 1 \mathrm{H}, \mathrm{NH}), 7.37\left(\mathrm{dt}, J=7.2,0.8 \mathrm{~Hz}, 1 \mathrm{H}, 1 \mathrm{H}_{\mathrm{ar}}\right), 7.44(\mathrm{dd}, J=7.6$, $\left.1.6 \mathrm{~Hz}, 1 \mathrm{H}, 1 \mathrm{H}_{\mathrm{ar}}\right), 7.83\left(\mathrm{dd}, J=8.0,1.2 \mathrm{~Hz}, 1 \mathrm{H}, 1 \mathrm{H}_{\mathrm{ar}}\right) \mathrm{ppm} ;{ }^{13} \mathrm{C} \mathrm{NMR}\left(100.6 \mathrm{MHz}, \mathrm{CDCl}_{3}\right) \delta=14.01$ $\left(\mathrm{CH}_{3}\right), 22.54\left(\mathrm{CH}_{2}\right), 26.84\left(\mathrm{CH}_{2}\right), 27.78\left(\mathrm{CH}_{2}\right), 31.42\left(\mathrm{CH}_{2}\right), 46.39\left(\mathrm{CH}_{2}-\mathrm{N}\right), 91.92\left(\mathrm{C}_{\mathrm{ar}}\right), 128.28\left(\mathrm{CH}_{\mathrm{ar}}\right)$, $128.35\left(\mathrm{CH}_{\mathrm{ar}}\right), 130.20\left(\mathrm{CH}_{\mathrm{ar}}\right), 139.62\left(\mathrm{CH}_{\mathrm{ar}}\right), 148.49\left(\mathrm{C}_{\mathrm{ar}}\right), 201.05(\mathrm{C}=\mathrm{S})$; IR: 3193, 3045, 2953, 2925, 2854, 1581, 1521, 1459, 1429, 1391, 1337, 1306, 1281, 1257, 1239, 1220, 1195, 1159, 1114, 1100, 1070, $1015 \mathrm{~cm}^{-1}$. Elemental Anal. Calcd for $\mathrm{C}_{13} \mathrm{H}_{18} \mathrm{INS}$ (347.258): C, 44.96; H, 5.22. Found: $\mathrm{C}, 44.60 ; \mathrm{H}, 5.30$.

$\mathrm{N}$-(3-methylbutyl)-o-iodobenzthioamide 5e

Yield: 26, 57\%; m.p. $69-71{ }^{\circ} \mathrm{C} ;{ }^{1} \mathrm{H}$ NMR $\left(400 \mathrm{MHz}, \mathrm{CDCl}_{3}\right) \delta=1.00\left(\mathrm{~d}, J=6.4 \mathrm{~Hz}, 6 \mathrm{H}, 2 \mathrm{CCH}_{3}\right)$, 1.64-1.69 (m, 2H, $\left.\mathrm{CH}_{2}\right), 1.73-1.80(\mathrm{~m}, 1 \mathrm{H}, \mathrm{CH}), 3.79-3.84\left(\mathrm{~m}, 2 \mathrm{H}, \mathrm{N}-\mathrm{CH}_{2}\right), 7.04(\mathrm{ddd}, J=8.0,7.2,2.0 \mathrm{~Hz}$, $\left.1 \mathrm{H}, 1 \mathrm{H}_{\mathrm{ar}}\right), 7.30(\mathrm{bs}, 1 \mathrm{H}, \mathrm{NH}), 7.36\left(\mathrm{dt}, J=7.2,1.2 \mathrm{~Hz}, 1 \mathrm{H}, 1 \mathrm{H}_{\mathrm{ar}}\right), 7.40\left(\mathrm{dd}, J=8.0,2.0 \mathrm{~Hz}, 1 \mathrm{H}, 1 \mathrm{H}_{\mathrm{ar}}\right), 7.81$ $\left(\mathrm{dd}, J=8.0,1.2 \mathrm{~Hz}, 1 \mathrm{H}, 1 \mathrm{H}_{\mathrm{ar}}\right) \mathrm{ppm} ;{ }^{13} \mathrm{C} \mathrm{NMR}\left(100.6 \mathrm{MHz}, \mathrm{CDCl}_{3}\right) \delta=22.48\left(2 \mathrm{xCH}_{3}\right), 26.14(\mathrm{CH}), 36.56$ $\left(\mathrm{CH}_{2}\right), 44.72\left(\mathrm{~N}-\mathrm{CH}_{2}\right), 92.04\left(\mathrm{C}_{\mathrm{ar}}\right), 128.21\left(\mathrm{CH}_{\mathrm{ar}}\right), 128.35\left(\mathrm{CH}_{\mathrm{ar}}\right), 130.20\left(\mathrm{CH}_{\mathrm{ar}}\right), 139.60\left(\mathrm{CH}_{\mathrm{ar}}\right), 148.39$ (Car), 200.90 (C=S); IR: 3197, 3050, 2955, 2929, 2866, 1542, 1454, 1428, 1384, 1361, 1339, 1327, 1308, 1278, $1263,1248,1213,1156,1068,1044,1014 \mathrm{~cm}^{-1}$. Elemental Anal. Calcd for $\mathrm{C}_{12} \mathrm{H}_{16} \mathrm{INS}$ (333.231): C, 43.25; H, 4.84. Found: C, 43.46; H, 4.83 .

$\mathrm{N}$-cyclohexyl-o-iodobenzthioamide $\mathbf{5 f}$

Yield: 41, 52\%; m.p. $138-141{ }^{\circ} \mathrm{C} ;{ }^{1} \mathrm{H}$ NMR $\left(700 \mathrm{MHz}, \mathrm{CDCl}_{3}\right): \delta=1.25-1.31(\mathrm{~m}, 1 \mathrm{H}, \mathrm{CH}), 1.37-1.41$ (m, 2H, $\left.\mathrm{CH}_{2}\right), 1.47-1.54\left(\mathrm{~m}, 2 \mathrm{H}, \mathrm{CH}_{2}\right), 1.69-1.72(\mathrm{~m}, 1 \mathrm{H}, \mathrm{CH}), 1.81-1.84\left(\mathrm{~m}, 2 \mathrm{H}, \mathrm{CH}_{2}\right), 2.27-2.28(\mathrm{~m}$, $\left.2 \mathrm{H}, \mathrm{CH}_{2}\right), 7.54-7.58(\mathrm{~m}, 1 \mathrm{H}, \mathrm{CH}), 7.05\left(\mathrm{dt}, J=7.0,1.4 \mathrm{~Hz}, 1 \mathrm{H}, 1 \mathrm{H}_{\mathrm{ar}}\right), 7.14(\mathrm{bs}, 1 \mathrm{H}, \mathrm{NH}), 7.38(\mathrm{dt}, J=7.0$, $\left.0.7 \mathrm{~Hz}, 1 \mathrm{H}, 1 \mathrm{H}_{\mathrm{ar}}\right), 7.45\left(\mathrm{dd}, J=7.7,1.4 \mathrm{~Hz}, 1 \mathrm{H}, 1 \mathrm{H}_{\mathrm{ar}}\right), 7.84\left(\mathrm{dd}, J=9.1,1.4 \mathrm{~Hz}, 1 \mathrm{H}, 1 \mathrm{H}_{\mathrm{ar}}\right) \mathrm{ppm} ;{ }^{13} \mathrm{C} \mathrm{NMR}$ $\left(100.6 \mathrm{MHz}, \mathrm{CDCl}_{3}\right): \delta=25.64\left(2 \mathrm{xCH}_{2}\right), 26.49\left(\mathrm{CH}_{2}\right), 32.33\left(2 \mathrm{xCH}_{2}\right), 55.66(\mathrm{CH}-\mathrm{N}), 92.84\left(\mathrm{C}_{\mathrm{ar}}\right), 129.24$ $\left(\mathrm{CH}_{\mathrm{ar}}\right), 129.35\left(\mathrm{CH}_{\mathrm{ar}}\right), 131.11\left(\mathrm{CH}_{\mathrm{ar}}\right), 140.62\left(\mathrm{CH}_{\mathrm{ar}}\right), 149.45\left(\mathrm{C}_{\mathrm{ar}}\right), 200.54(\mathrm{C}=\mathrm{S}) \mathrm{ppm}$; IR: 3202, 3039, 2924, 2852, 1533, 1459, 1445, 1426, 1382, 1358, 1344, 1309, 1277, 1260, 1251, 1227, 1152, 1093, 1044, $1013 \mathrm{~cm}^{-1}$. Elemental Anal. Calcd for $\mathrm{C}_{13} \mathrm{H}_{16} \mathrm{INS}$ (345.242): C, 45.23; H, 4.67. Found: $\mathrm{C}, 45.63 ; \mathrm{H}, 4.53$.

\subsubsection{Synthesis of Benzisoselenazol-3(2H)-ones $\mathbf{6 a}, \mathbf{6} \mathbf{b}$ and $\mathbf{6 d}$}

Hydrazine hydrate $(8.0 \mathrm{mmol})$ was added dropwise to the mixture of selenium powder $(1.2 \mathrm{mmol})$ and lithium hydroxide $(3.6 \mathrm{mmol})$ in DMF $(3 \mathrm{~mL})$. Reaction was heated to $120^{\circ} \mathrm{C}$ and stirred for $15 \mathrm{~min}$ under argon atmosphere. After cooling to room temperature, the amide $(1.0 \mathrm{mmol})$ in DMF $(2 \mathrm{~mL})$ was added. The reaction mixture was heated to $120^{\circ} \mathrm{C}$ and stirred for $20 \mathrm{~h}$ under argon atmosphere. The solution was cooled, $25 \mathrm{~mL}$ of brine was added and the mixture was stirred for an additional $20 \mathrm{~h}$. Precipitate was filtered under vacuum, washed with water and dried in air. The crude product was purified by column chromatography (silica gel, DCM). Synthesis and characterization of compounds $\mathbf{6 c}, \mathbf{6 e}$ and $\mathbf{6 f}$ are described in our previous paper [24]. 
$N$-ethyl-1,2-benzisoselenazol-3(2H)-one 6a

Yield: 68\%; m.p. 93-96 ${ }^{\circ} \mathrm{C}$, (lit. [32] m.p. 92-94 $\left.{ }^{\circ} \mathrm{C}\right) ;{ }^{1} \mathrm{H} \mathrm{NMR}\left(400 \mathrm{MHz}, \mathrm{CDCl}_{3}\right) \delta=1.34$ (t, $\left.J=7.2 \mathrm{~Hz}, 3 \mathrm{H}, \mathrm{CH}_{3}\right), 3.88-3.93\left(\mathrm{~m}, 2 \mathrm{H}, \mathrm{N}-\mathrm{CH}_{2}\right), 7.41\left(\mathrm{ddd}, J=7.6,7.2,1.2 \mathrm{~Hz}, 1 \mathrm{H}, 1 \mathrm{H}_{\mathrm{ar}}\right), 7.57(\mathrm{ddd}$, $\left.J=7.6,7.2,1.2 \mathrm{~Hz}, 1 \mathrm{H}, 1 \mathrm{H}_{\mathrm{ar}}\right), 7.66\left(\mathrm{dt}, J=8.0,0.8 \mathrm{~Hz}, 1 \mathrm{H}, 1 \mathrm{H}_{\mathrm{ar}}\right), 8.04\left(\mathrm{ddd}, J=8.0,1.2,0.8,1 \mathrm{H}, 1 \mathrm{H}_{\mathrm{ar}}\right)$ ppm; ${ }^{13} \mathrm{C}$ NMR $\left(100.6 \mathrm{MHz}, \mathrm{CDCl}_{3}\right) \delta=15.66\left(\mathrm{CH}_{3}\right), 39.85\left(\mathrm{CH}_{2}-\mathrm{N}\right), 124.09\left(\mathrm{CH}_{\mathrm{ar}}\right), 126.17\left(\mathrm{CH}_{\mathrm{ar}}\right)$, 127.72 ( $\left.\mathrm{C}_{\mathrm{ar}}\right), 128.71\left(\mathrm{CH}_{\mathrm{ar}}\right), 131.83\left(\mathrm{CH}_{\mathrm{ar}}\right), 137.68\left(\mathrm{C}_{\mathrm{ar}}\right), 166.93(\mathrm{C}=\mathrm{O}) \mathrm{ppm} ;{ }^{77} \mathrm{Se}\left(76.3 \mathrm{MHz}, \mathrm{CDCl}_{3}\right)$, $\delta=877.01 \mathrm{ppm}$.

$N$-propyl-1,2-benzisoselenazol-3(2H)-one $\mathbf{6 b}$

Yield: $81 \%$; m.p. $71-71{ }^{\circ} \mathrm{C}$, (lit. [32] m.p. $\left.70-72{ }^{\circ} \mathrm{C}\right) ;{ }^{1} \mathrm{H}$ NMR $\left(700 \mathrm{MHz}, \mathrm{CDCl}_{3}\right) \delta=1.00$ (t, $\left.J=7.7 \mathrm{~Hz}, 3 \mathrm{H}, \mathrm{CH}_{3}\right), 1.73-1.79\left(\mathrm{~m}, 2 \mathrm{H}, \mathrm{CH}_{2}\right), 3.83\left(\mathrm{t}, J=7.7 \mathrm{~Hz}, 2 \mathrm{H}, \mathrm{N}-\mathrm{CH}_{2}\right), 7.42(\mathrm{ddd}, J=7.0,7.0$, $\left.0.7 \mathrm{~Hz}, 1 \mathrm{H}, 1 \mathrm{H}_{\mathrm{ar}}\right), 7.58\left(\mathrm{ddd}, J=7.0,7.0,1.4 \mathrm{~Hz}, 1 \mathrm{H}, 1 \mathrm{H}_{\mathrm{ar}}\right), 7.63\left(\mathrm{dd}, J=9.1,1.4 \mathrm{~Hz}, 1 \mathrm{H}, 1 \mathrm{H}_{\mathrm{ar}}\right), 8.05$ $\left(\mathrm{dd}, J=7.7,0.7 \mathrm{~Hz}, 1 \mathrm{H}, 1 \mathrm{H}_{\mathrm{ar}}\right) \mathrm{ppm} ;{ }^{13} \mathrm{C} \mathrm{NMR}\left(100.6 \mathrm{MHz}, \mathrm{CDCl}_{3}\right) \delta=11.16\left(\mathrm{CH}_{3}\right), 23.89\left(\mathrm{CH}_{2}\right), 46.47$ $\left(\mathrm{CH}_{2}-\mathrm{N}\right), 123.92\left(\mathrm{CH}_{\mathrm{ar}}\right), 126.17\left(\mathrm{CH}_{\mathrm{ar}}\right), 127.67\left(\mathrm{C}_{\mathrm{ar}}\right), 128.87\left(\mathrm{CH}_{\mathrm{ar}}\right), 131.84\left(\mathrm{CH}_{\mathrm{ar}}\right), 137.63\left(\mathrm{C}_{\mathrm{ar}}\right), 167.20$ $(\mathrm{C}=\mathrm{O}) \mathrm{ppm} ;{ }^{77} \mathrm{Se}\left(76.3 \mathrm{MHz}, \mathrm{CDCl}_{3}\right), \delta=884.45 \mathrm{ppm}$.

N-hexyl-1,2-benzisoselenazol-3(2H)-one $6 \mathbf{d}$

Yield: 72\%; m.p. 83-85 ${ }^{\circ} \mathrm{C}$, (lit. [33] m.p. 84-85 $\left.{ }^{\circ} \mathrm{C}\right) ;{ }^{1} \mathrm{H}$ NMR $\left(400 \mathrm{MHz}, \mathrm{CDCl}_{3}\right) \delta=0.90(\mathrm{t}$, $\left.J=7.2 \mathrm{~Hz}, 3 \mathrm{H}, \mathrm{CH}_{3}\right), 1.32-1.43\left(\mathrm{~m}, 6 \mathrm{H}, 3 \mathrm{xCH}_{2}\right), 1.70-1.77\left(\mathrm{~m}, 2 \mathrm{H}, \mathrm{CH}_{2}\right), 3.87\left(\mathrm{t}, J=7.2 \mathrm{~Hz}, 2 \mathrm{H}, \mathrm{N}-\mathrm{CH}_{2}\right)$, $7.41-7.46\left(\mathrm{~m}, 1 \mathrm{H}, 1 \mathrm{H}_{\mathrm{ar}}\right), 7.59\left(\mathrm{dt}, J=6.8,1.6 \mathrm{~Hz}, 1 \mathrm{H}, 1 \mathrm{H}_{\mathrm{ar}}\right), 7.65\left(\mathrm{ddd}, J=8.0,1.2,0.8 \mathrm{~Hz}, 1 \mathrm{H}, 1 \mathrm{H}_{\mathrm{ar}}\right), 8.05$ $\left(\mathrm{ddd}, J=8.0,1.2,0.8 \mathrm{~Hz}, 1 \mathrm{H}, 1 \mathrm{H}_{\mathrm{ar}}\right) \mathrm{ppm} ;{ }^{13} \mathrm{C} \mathrm{NMR}\left(100.6 \mathrm{MHz}, \mathrm{CDCl}_{3}\right) \delta=13.99\left(\mathrm{CH}_{3}\right), 22.50\left(\mathrm{CH}_{2}\right)$, $26.30\left(\mathrm{CH}_{2}\right), 30.55\left(\mathrm{CH}_{2}\right), 31.45\left(\mathrm{CH}_{2}\right), 44.89\left(\mathrm{CH}_{2}-\mathrm{N}\right), 123.93\left(\mathrm{CH}_{\mathrm{ar}}\right), 126.16\left(\mathrm{CH}_{\mathrm{ar}}\right), 127.70\left(\mathrm{C}_{\mathrm{ar}}\right), 128.84$ $\left(\mathrm{CH}_{\mathrm{ar}}\right), 131.82\left(\mathrm{CH}_{\mathrm{ar}}\right), 137.64\left(\mathrm{C}_{\mathrm{ar}}\right), 167.13(\mathrm{C}=\mathrm{O}) \mathrm{ppm} ;{ }^{77} \mathrm{Se}\left(76.3 \mathrm{MHz}, \mathrm{CDCl}_{3}\right), \delta=883.31 \mathrm{ppm}$.

\subsubsection{Synthesis of Benzisoselenazol-3(2H)-thiones $\mathbf{7 a - 7 f}$}

Method E: Hydrazine hydrate $(8.0 \mathrm{mmol})$ was added dropwise to the mixture of selenium powder $(1.2 \mathrm{mmol})$ and lithium hydroxide $(3.6 \mathrm{mmol})$ in DMF $(3 \mathrm{~mL})$. Reaction was heated to $120^{\circ} \mathrm{C}$ and stirred for $15 \mathrm{~min}$ under argon atmosphere. After cooling to room temperature, the thioamide (1.0 $\mathrm{mmol})$ in DMF ( $2 \mathrm{~mL}$ ) was added. The reaction mixture was heated to $120{ }^{\circ} \mathrm{C}$ and stirred for $20 \mathrm{~h}$ under argon atmosphere. The solution was cooled, $25 \mathrm{~mL}$ of brine was added and the mixture was stirred for additional $20 \mathrm{~h}$. The crude product was extracted with DCM combined organic layers were washed with water to remove DMF, dried with magnesium sulfate and evaporated. The crude product was purified by column chromatography (silica gel, DCM/hexane, 80:20).

Method F: To a solution of benzisoselenazolone $(1.0 \mathrm{mmol})$ in toluene $(10 \mathrm{~mL})$ Lawesson's reagent $(0.70 \mathrm{mmol})$ was added portionwise and the mixture was stirred overnight at $120^{\circ} \mathrm{C}$. Solvent was removed under vacuum and the resulting crude product was purified by silica gel column chromatography (solvent: $\mathrm{CHCl}_{3}$ ).

$N$-ethyl-1,2-benzisoselenazol-3(2H)-thione 7a

Yield: 34, 21\%; yellow oil; ${ }^{1} \mathrm{H}$ NMR $\left(400 \mathrm{MHz}, \mathrm{CDCl}_{3}\right) \delta=1.48\left(\mathrm{t}, J=7.2 \mathrm{~Hz}, 3 \mathrm{H}, \mathrm{CH}_{3}\right), 3.57-3.61$ $\left(\mathrm{m}, 2 \mathrm{H}, \mathrm{N}-\mathrm{CH}_{2}\right), 7.35\left(\mathrm{t}, J=7.2 \mathrm{~Hz}, 1 \mathrm{H}, 1 \mathrm{H}_{\mathrm{ar}}\right), 7.48\left(\mathrm{t}, J=6.8 \mathrm{~Hz}, 1 \mathrm{H}, 1 \mathrm{H}_{\mathrm{ar}}\right), 7.55(\mathrm{~d}, J=8.0 \mathrm{~Hz}, 1 \mathrm{H}$, $\left.1 \mathrm{H}_{\mathrm{ar}}\right), 8.08\left(\mathrm{bs}, 1 \mathrm{H}, 1 \mathrm{H}_{\mathrm{ar}}\right) \mathrm{ppm} ;{ }^{13} \mathrm{C} \mathrm{NMR}\left(100.6 \mathrm{MHz}, \mathrm{CDCl}_{3}\right) \delta=16.48\left(\mathrm{CH}_{3}\right), 51.33\left(\mathrm{CH}_{2}-\mathrm{N}\right), 126.79$ $\left(\mathrm{CH}_{\mathrm{ar}}\right), 126.93\left(\mathrm{CH}_{\mathrm{ar}}\right), 129.45\left(\mathrm{CH}_{\mathrm{ar}}\right), 132.33\left(\mathrm{CH}_{\mathrm{ar}}\right), 135.30\left(\mathrm{C}_{\mathrm{ar}}\right), 140.96\left(\mathrm{C}_{\mathrm{ar}}\right), 164.91(\mathrm{C}=\mathrm{S}) \mathrm{ppm} ;{ }^{77} \mathrm{Se}$ $\left(76.3 \mathrm{MHz}, \mathrm{CDCl}_{3}\right), \delta=527.74 \mathrm{ppm}[20]$.

$N$-propyl-1,2-benzisoselenazol-3(2H)-thione $7 \mathbf{b}$

Yield: 62, 32\%; yellow oil; ${ }^{1} \mathrm{H}$ NMR $\left(700 \mathrm{MHz}, \mathrm{CDCl}_{3}\right) \delta=1.10\left(\mathrm{t}, J=7.0 \mathrm{~Hz}, 3 \mathrm{H}, \mathrm{CH}_{3}\right), 1.88-1.93$ $\left(\mathrm{m}, 2 \mathrm{H}, \mathrm{CH}_{2}\right), 3.50\left(\mathrm{t}, J=7.0 \mathrm{~Hz}, 2 \mathrm{H}, \mathrm{N}-\mathrm{CH}_{2}\right), 7.35\left(\mathrm{t}, J=7.0 \mathrm{~Hz}, 1 \mathrm{H}, 1 \mathrm{H}_{\mathrm{ar}}\right), 7.47\left(\mathrm{t}, J=7.0 \mathrm{~Hz}, 1 \mathrm{H}, 1 \mathrm{H}_{\mathrm{ar}}\right)$, $7.56\left(\mathrm{~d}, J=8.4 \mathrm{~Hz}, 1 \mathrm{H}, 1 \mathrm{H}_{\mathrm{ar}}\right), 8.09\left(\mathrm{bs}, 1 \mathrm{H}, 1 \mathrm{H}_{\mathrm{ar}}\right) \mathrm{ppm} ;{ }^{13} \mathrm{C} \mathrm{NMR}\left(100.6 \mathrm{MHz}, \mathrm{CDCl}_{3}\right) \delta=12.22\left(\mathrm{CH}_{3}\right)$, 
$23.95\left(\mathrm{CH}_{2}\right), 57.82\left(\mathrm{CH}_{2}-\mathrm{N}\right), 125.80\left(\mathrm{CH}_{\mathrm{ar}}\right), 125.85\left(\mathrm{CH}_{\mathrm{ar}}\right), 128.45\left(\mathrm{CH}_{\mathrm{ar}}\right), 131.20\left(\mathrm{CH}_{\mathrm{ar}}\right), 134.45\left(\mathrm{C}_{\mathrm{ar}}\right)$, $139.95\left(\mathrm{C}_{\mathrm{ar}}\right), 163.81(\mathrm{C}=\mathrm{S}) \mathrm{ppm} ;{ }^{77} \mathrm{Se}\left(76.3 \mathrm{MHz}, \mathrm{CDCl}_{3}\right), \delta=525.91 \mathrm{ppm}[20]$.

N-butyl-1,2-benzisoselenazol-3(2H)-thione 7c

Yield: 40, 38\%; yellow oil; ${ }^{1} \mathrm{H}$ NMR $\left(700 \mathrm{MHz}, \mathrm{CDCl}_{3}\right) \delta=0.99\left(\mathrm{t}, J=7.0 \mathrm{~Hz}, 3 \mathrm{H}, \mathrm{CH}_{3}\right), 1.48-1.53$ $\left(\mathrm{m}, 2 \mathrm{H}, \mathrm{CH}_{2}\right), 1.80-1.84\left(\mathrm{~m}, 2 \mathrm{H}, \mathrm{CH}_{2}\right), 3.51\left(\mathrm{t}, J=7.0 \mathrm{~Hz}, 2 \mathrm{H}, \mathrm{N}-\mathrm{CH}_{2}\right), 7.31\left(\mathrm{dt}, J=7.7,0.7 \mathrm{~Hz}, 1 \mathrm{H}, 1 \mathrm{H}_{\mathrm{ar}}\right)$, $7.43\left(\mathrm{td}, J=8.4,1.4 \mathrm{~Hz}, 1 \mathrm{H}, 1 \mathrm{H}_{\mathrm{ar}}\right), 7.51\left(\mathrm{~d}, J=7.7 \mathrm{~Hz}, 1 \mathrm{H}, 1 \mathrm{H}_{\mathrm{ar}}\right), 8.05\left(\mathrm{bs}, 1 \mathrm{H}, 1 \mathrm{H}_{\mathrm{ar}}\right) \mathrm{ppm} ;{ }^{13} \mathrm{C} \mathrm{NMR}$ $\left(100.6 \mathrm{MHz}, \mathrm{CDCl}_{3}\right) \delta=13.97\left(\mathrm{CH}_{3}\right), 20.80\left(\mathrm{CH}_{2}\right), 32.67\left(\mathrm{CH}_{2}\right), 55.77\left(\mathrm{CH}_{2}-\mathrm{N}\right), 125.82\left(\mathrm{CH}_{\mathrm{ar}}\right), 125.87$ $\left(\mathrm{CH}_{\mathrm{ar}}\right), 128.45\left(\mathrm{CH}_{\mathrm{ar}}\right), 131.23\left(\mathrm{CH}_{\mathrm{ar}}\right), 134.44\left(\mathrm{C}_{\mathrm{ar}}\right), 139.96\left(\mathrm{C}_{\mathrm{ar}}\right), 163.95(\mathrm{C}=\mathrm{S}) \mathrm{ppm} ;{ }^{77} \mathrm{Se}(76.3 \mathrm{MHz}$, $\left.\mathrm{CDCl}_{3}\right), \delta=526.60 \mathrm{ppm}[20]$.

$N$-hexyl-1,2-benzisoselenazol-3(2H)-thione $7 \mathbf{d}$

Yield: 51, 20\%; yellow oil; ${ }^{1} \mathrm{H}$ NMR $\left(700 \mathrm{MHz}, \mathrm{CDCl}_{3}\right) \delta=0.91\left(\mathrm{t}, J=7.0 \mathrm{~Hz}, 3 \mathrm{H}, \mathrm{CH}_{3}\right), 1.33-1.38$ $\left(\mathrm{m}, 4 \mathrm{H}, 2 \mathrm{xCH}_{2}\right), 1.45-1.50\left(\mathrm{~m}, 2 \mathrm{H}, \mathrm{CH}_{2}\right), 1.81-1.85\left(\mathrm{~m}, 2 \mathrm{H}, \mathrm{CH}_{2}\right), 3.50\left(\mathrm{t}, J=7.0 \mathrm{~Hz}, 2 \mathrm{H}, \mathrm{N}-\mathrm{CH}_{2}\right), 7.31(\mathrm{t}$, $\left.J=7.7 \mathrm{~Hz}, 1 \mathrm{H}, 1 \mathrm{H}_{\mathrm{ar}}\right), 7.44\left(\mathrm{t}, J=7.0 \mathrm{~Hz}, 1 \mathrm{H}, 1 \mathrm{H}_{\mathrm{ar}}\right), 7.52\left(\mathrm{~d}, J=7.7 \mathrm{~Hz}, 1 \mathrm{H}, 1 \mathrm{H}_{\mathrm{ar}}\right), 8.02\left(\mathrm{bs}, 1 \mathrm{H}, 1 \mathrm{H}, 1 \mathrm{H}_{\mathrm{ar}}\right)$ ppm; ${ }^{13} \mathrm{C} \mathrm{NMR}\left(100.6 \mathrm{MHz}, \mathrm{CDCl}_{3}\right) \delta=14.10\left(\mathrm{CH}_{3}\right), 22.67\left(\mathrm{CH}_{2}\right), 27.34\left(\mathrm{CH}_{2}\right), 30.51\left(\mathrm{CH}_{2}\right), 31.69\left(\mathrm{CH}_{2}\right)$, $56.13\left(\mathrm{CH}_{2}-\mathrm{N}\right), 125.79\left(\mathrm{CH}_{\mathrm{ar}}\right), 125.88\left(\mathrm{CH}_{\mathrm{ar}}\right), 128.47\left(\mathrm{CH}_{\mathrm{ar}}\right), 131.24\left(\mathrm{CH}_{\mathrm{ar}}\right), 134.41\left(\mathrm{C}_{\mathrm{ar}}\right), 139.94\left(\mathrm{C}_{\mathrm{ar}}\right)$, 163.67 (C=S) ppm; ${ }^{77} \mathrm{Se}\left(76.3 \mathrm{MHz}, \mathrm{CDCl}_{3}\right), \delta=525.70 \mathrm{ppm}$; IR: 3048, 3009, 2952, 2922, 2853, 1606, 1582, 1555, 1460, 1434, 1402, 1375, 1347, 1314, 1299, 1278, 1254, 1241, 1200, 1159, 1121, 1078, 1041, $1016 \mathrm{~cm}^{-1}$. Elemental Anal. Calcd for $\mathrm{C}_{13} \mathrm{H}_{17} \mathrm{NSSe}$ (298.306): C, 52.34; H, 5.74. Found: C, 52.03; H, 5.65.

$\mathrm{N}$-(3-methylbutyl)-1,2-benzisoselenazol-3(2H)-thione 7e

Yield: 43, 25\%; yellow oil; ${ }^{1} \mathrm{H}$ NMR $\left(700 \mathrm{MHz}, \mathrm{CDCl}_{3}\right) \delta=0.99\left(\mathrm{~d}, J=7.0 \mathrm{~Hz}, 6 \mathrm{H}, 2 \mathrm{CCH}_{3}\right), 1.72-1.75$ $\left(\mathrm{m}, 2 \mathrm{H}, \mathrm{CH}_{2}\right), 1.80-821 .(\mathrm{m}, 1 \mathrm{H}, \mathrm{CH}), 3.53\left(\mathrm{t}, J=7.0 \mathrm{~Hz}, 2 \mathrm{H}, \mathrm{N}-\mathrm{CH}_{2}\right), 7.31\left(\mathrm{t}, J=7.7 \mathrm{~Hz}, 1 \mathrm{H}, 1 \mathrm{H}_{\mathrm{ar}}\right), 7.43$ $\left(\mathrm{dt}, J=7.7,0.7 \mathrm{~Hz}, 1 \mathrm{H}, 1 \mathrm{H}_{\mathrm{ar}}\right), 7.52\left(\mathrm{~d}, J=8.4 \mathrm{~Hz}, 1 \mathrm{H}, 1 \mathrm{H}_{\mathrm{ar}}\right), 8.03\left(\mathrm{bs}, 1 \mathrm{H}, 1 \mathrm{H}_{\mathrm{ar}}\right) \mathrm{ppm} ;{ }^{13} \mathrm{C} \mathrm{NMR}(100.6$ $\left.\mathrm{MHz}, \mathrm{CDCl}_{3}\right) \delta=22.63\left(2 \times \mathrm{CH}_{3}\right), 26.34(\mathrm{CH}), 39.34\left(\mathrm{CH}_{2}\right), 54.31\left(\mathrm{CH}_{2}-\mathrm{N}\right), 125.79\left(\mathrm{CH}_{\mathrm{ar}}\right), 125.87\left(\mathrm{CH}_{\mathrm{ar}}\right)$, $128.46\left(\mathrm{CH}_{\mathrm{ar}}\right), 131.22\left(\mathrm{CH}_{\mathrm{ar}}\right), 134.44\left(\mathrm{C}_{\mathrm{ar}}\right), 139.96\left(\mathrm{C}_{\mathrm{ar}}\right), 163.83(\mathrm{C}=\mathrm{S}) \mathrm{ppm} ;{ }^{77} \mathrm{Se}\left(76.3 \mathrm{MHz}, \mathrm{CDCl}_{3}\right)$, $\delta=526.38$ ppm; IR: 2952, 2922, 2866, 1608, 1582, 1523, 1460, 1437, 1383, 1364, 1327, 1299, 1265, 1218, 1158, 1128, 1047, 1023, $1007 \mathrm{~cm}^{-1}$. Elemental Anal. Calcd for $\mathrm{C}_{12} \mathrm{H}_{15} \mathrm{NSSe}$ (284.279): C, 50.70; H, 5.32 . Found: C, 50.41; H, 5.37.

$\mathrm{N}$-cyclohexyl-1,2-benzisoselenazol-3(2H)-thione $7 f$

Yield: 35, 53\%; yellow oil; $1 \mathrm{H}$ NMR $\left(400 \mathrm{MHz}, \mathrm{CDCl}_{3}\right): \delta=1.33-1.38(\mathrm{~m}, 1 \mathrm{H}, \mathrm{CH}), 1.38-1.50(\mathrm{~m}$, $\left.2 \mathrm{H}, \mathrm{CH}_{2}\right), 1.54-1.62\left(\mathrm{~m}, 2 \mathrm{H}, \mathrm{CH}_{2}\right), 1.69-1.72(\mathrm{~m}, 1 \mathrm{H}, \mathrm{CH}), 1.85-1.95\left(\mathrm{~m}, 4 \mathrm{H}, 2 \times \mathrm{CH}_{2}\right), 3.45-3.52(\mathrm{~m}, 1 \mathrm{H}$, $\mathrm{N}-\mathrm{CH}), 7.31\left(\mathrm{dt}, J=8.0,1.2 \mathrm{~Hz}, 1 \mathrm{H}, 1 \mathrm{H}_{\mathrm{ar}}\right), 7.44\left(\mathrm{dt}, J=6.8,1.2 \mathrm{~Hz}, 1 \mathrm{H}, 1 \mathrm{H}_{\mathrm{ar}}\right), 7.51(\mathrm{~d}, J=8.0 \mathrm{~Hz}, 1 \mathrm{H}$, $\left.1 \mathrm{H}_{\mathrm{ar}}\right), 8.05\left(\mathrm{~d}, J=7.2 \mathrm{~Hz}, 1 \mathrm{H}, 1 \mathrm{H}_{\mathrm{ar}}\right) \mathrm{ppm} ;{ }^{13} \mathrm{C} \mathrm{NMR}\left(100.6 \mathrm{MHz}, \mathrm{CDCl}_{3}\right): \delta=24.67\left(2 \mathrm{xCH}_{2}\right), 25.79\left(\mathrm{CH}_{2}\right)$, $32.78\left(2 \mathrm{xCH}_{2}\right), 65.60(\mathrm{CH}-\mathrm{N}), 125.75\left(\mathrm{CH}_{\mathrm{ar}}\right), 125.81\left(\mathrm{CH}_{\mathrm{ar}}\right), 128.82\left(\mathrm{CH}_{\mathrm{ar}}\right), 131.20\left(\mathrm{CH}_{\mathrm{ar}}\right), 134.68\left(\mathrm{C}_{\mathrm{ar}}\right)$, $139.77\left(\mathrm{C}_{\mathrm{ar}}\right), 161.22(\mathrm{C}=\mathrm{S}) \mathrm{ppm} ;{ }^{77} \mathrm{Se}\left(76.3 \mathrm{MHz}, \mathrm{CDCl}_{3}\right), \delta=514.27$ ppm; IR: 2926, 2850, 1438, 1384, 1345, 1277, 1257, 1240, 1127, 1099, $1019 \mathrm{~cm}^{-1}$. Elemental Anal. Calcd for $\mathrm{C}_{13} \mathrm{H}_{15} \mathrm{NSSe}$ (296.290): C, 52.70; H, 5.10. Found: C, 52.97; H, 5.04.

\subsection{Biological Activity Evaluation}

\subsubsection{Antioxidant Activity Assay}

To a solution of compounds and 16-25 $(0.015 \mathrm{mmol})$ and dithiothreitole DTT ${ }^{\text {red }}(0.15 \mathrm{mmol})$ in $1.1 \mathrm{~mL}$ of $\mathrm{CD}_{3} \mathrm{OD} 30 \% \mathrm{H}_{2} \mathrm{O}_{2}(0.15 \mathrm{mmol})$ was added. ${ }^{1} \mathrm{H}$ NMR spectra were measured right after the addition of hydrogen peroxide and then in specific time intervals. The concentration of the substrate was determined according to the changes in the integration on the ${ }^{1} \mathrm{H}$ NMR spectra. [27] 


\subsubsection{SRB viability Assay}

\section{Cell Culture}

The prostate cancer cell line DU-145 was purchased from the American Type Culture Collection (ATTC, Manassas, VA, USA). The DU-145 cells were cultured in MEME medium supplemented with $10 \%$ fetal bovine serum, $1 \%$ penicillin/streptomycin, $2 \mathrm{mM}$ glutamine and $1 \mathrm{mM}$ sodium pyruvate at $37^{\circ} \mathrm{C}$. The PNT1A cells were cultured in RPMI 1640 supplemented with serum, L-glutamine and antibiotics. The cells were maintained at $37{ }^{\circ} \mathrm{C}$ in an atmosphere containing $5 \% \mathrm{CO}_{2}$. Stock solutions of $\mathrm{N}$-substituted ebselen derivatives were prepared in (0.1\%) DMSO.

\section{SRB Assay}

Cell viability was measured by Sulphorhodamine B (SRB) assay. The cells were grown to sub-confluent levels at the certain culture medium and then seeded into 96-well plates at $6.0 \times 10^{3}$ cells/well in the final volume of $200 \mu \mathrm{L}$ in the culture medium for $24 \mathrm{~h}$. Then, they were treated with various concentrations $(2.5,5,10,20,30,40 \mu \mathrm{L})$ of $N$-substituted ebelsen derivatives for the next $24 \mathrm{~h}$. After incubation, the cells were fixed in $20 \%$ trichloroacetic acid for an $1 \mathrm{~h}$. The plates were washed with distilled water and 0.4\% SRB (Sigma Aldrich, St. Louis, MO, USA) in 1\% acetic acid solution was added to the plates for $15 \mathrm{~min}$. The SRB solution was washed with $1 \%$ acetic acid. SRB was then solubilized in $10 \mathrm{mM}$ Trisma-base solution and the absorbance was measured at $570 \mathrm{~nm}$ using an automated microplate reader. The experiments were done in triplates and the $\mathrm{IC}_{50}$ values were calculated.

\section{Conclusions}

We have designed a new efficient two-step method to obtain a series of $N$-alkyl benzisoselenazol$3(2 \mathrm{H})$-thiones. The first step involving the conversion of $\mathrm{N}$-substituted benzamides to their thiocarbonyl analogues has been significantly upgraded by applying microwave irradiation. The further conversion to corresponding benzisoselenazolthiones was efficiently conducted by our previously presented procedure using dilithium diselenide as the nucleophile. We have obtained a series of $N$-alkyl benzisoselenazolthiones and tested them as catalysts for $\mathrm{H}_{2} \mathrm{O}_{2}$ reduction, using a commonly used DTT assay, and cytotoxic agents on prostate cancer cell line DU145 and non-cancerous cell line PNT1A. The N-propyl $\mathbf{7 b}$ and $N$-3-methylbuthyl benzisoselenazolthione $7 \mathbf{e}$ were the most efficient antioxidants. In comparison to the previously tested corresponding carbonyl derivatives, it can be concluded that propyl and 3-methylbuthyl carbon chains, and the introduction of the sulfur atom increase the ability to catalytically reduce $\mathrm{H}_{2} \mathrm{O}_{2}$. The highest anti-proliferative activity was evaluated for $\mathrm{N}$-cyclohexylbenzisoselenazolthione $7 \mathrm{f}$. This result proves our previous observation, concerning the cytotoxic activity of $\mathrm{N}$-alkylbenzisoselenazolones, that the presence of the $\mathrm{N}$-cyclohexyl moiety is correlated with high cytotoxic potential.

Supplementary Materials: Supplementary materials are available online.

Author Contributions: Conceptualization, J.Ś.; Data curation, M.O. and A.J.P.; Formal analysis, M.O. and A.J.P.; Investigation, M.O., A.J.P., U.J. and J.A.; Writing—original draft, A.J.P.; Writing—review \& editing, J.Ś.

Funding: This work was supported by the National Science Centre, Poland, grant No. UMO-2015/17/ B/NZ7/03058.

Acknowledgments: Dedicated to Janusz Zakrzewski on the occasion of his 70th birthday.

Conflicts of Interest: The authors declare no conflict of interest.

\section{References}

1. Sies, H.; Berndt, C.; Jones, D.P. Oxidative Stress. Annu. Rev. Biochem. 2017, 86, 715-748. [CrossRef] [PubMed] 
2. Weekley, C.M.; Harris, H.H. Which form is that? The importance of selenium speciation and metabolism in the prevention and treatment of disease. Chem. Soc. Rev. 2013, 42, 8870-8894. [CrossRef] [PubMed]

3. Uzarewicz, A.; Wyżlic, I.; Ścianowski, J. Synthesis and reactions of organic-compounds with a nitrogen atom Part 10. Synthesis of allylic 1,2-ditoluene-sulfonamide, 1,2-diamine, hydroxy-1,2-ditoluenesulfonamide and hydroxy-1,2-diamine from (+)- $\alpha$-phellandrene. Pol. J. Chem. 1995, 69, 681-684. [CrossRef]

4. Ścianowski, J.; Rafiński, Z.; Wojtczak, A. Syntheses and reactions of new optically active terpene dialkyl diselenides. Eur. J. Org. Chem. 2006, 14, 3216-3225. [CrossRef]

5. Skowronek, P.; Ścianowski, J.; Gawroński, J. Helicity discrimination in diselenides by chiral substituents-A circular dichroism study. Tetrahedron Asymmetry 2006, 17, 2408-2412. [CrossRef]

6. Ścianowski, J.; Rafalski, J.; Banach, A.; Czaplewska, J.; Komoszyńska, A. Synthesis and reactions of the optically active selenols derived from monoterpenes. Tetrahedron Asymmetry 2013, 24, 1089-1096. [CrossRef]

7. Banach, A.; Ścianowski, J.; Uzarewicz-Baig, M.; Wojtczak, A. Terpenyl Selenides: Synthesis and Application in Asymmetric Epoxidation. Eur. J. Org. Chem. 2015, 16, 3477-3485. [CrossRef]

8. Pacuła, A.J.; Mangiavacchi, F.; Sancineto, L.; Lenardao, E.J.; Ścianowski, J.; Santi, C. An update on "selenium containing compounds from poison to drug candidates: A review on the GPx-like activity". Curr. Chem. Biol. 2015, 9, 97-112. [CrossRef]

9. Parnham, J.M.; Sies, H. The early research and development of ebselen. Biochem. Pharm. 2013, 86, 1248-1253. [CrossRef] [PubMed]

10. Kil, J.; Lobaris, E.; Spankovich, C.; Griffiths, S.; Antonelli, P.J.; Lynch, E.D.; Le Prell, C.G. Safety and efficacy of ebselen for the prevention of noise-induced hearing loss: A randomised, double-blind, placebo-controlled, phase 2 trial. Lancet 2017, 390, 969-979. [CrossRef]

11. Singh, N.; Sharpley, N.; Emir, A.L.; Masaki, U.E.; Herzallah, C.; Gluck, M.M.; Sharp, M.A.; Hamer, T.; Vasudevan, C.J.; Coven, S.R.; et al. Effect of the putative lithium mimetic ebselen on brain myo-inositol, sleep, and emotional processing in humans. Neuropsychopharmacology 2016, 41, 1768-1778. [CrossRef] [PubMed]

12. Orian, L.; Toppo, S. Organochalcogen peroxidase mimetics as potential drugs: A long story of a promise still unfulfilled. Free Rad. Biol. Med. 2014, 66, 65-74. [CrossRef] [PubMed]

13. Wolters, L.P.; Orian, L. Peroxidase Activity of Organic Selenides: Mechanistic Insights from Quantum. Chem. Curr. Org. Chem. 2016, 20, 189-197. [CrossRef]

14. Gandin, V.; Khalkar, P.; Braude, J.; Fernances, A.P. Organic selenium compounds as potential chemotherapeutic agents for improved cancer treatment. Free Rad. Biol. Med. 2018. [CrossRef] [PubMed]

15. Fuentes-Aguilar, A.; Romero-Hernández, L.L.; Arenas-González, A.; Merino-Montiel, P.; Montiel-Smith, S.; Meza-Reyes, S.; Vega-Báez, J.L.; Plata, G.B.; Padrón, J.M.; López, Ó.; et al. New selenosteroids as antiproliferative agents. Org. Biomol. Chem. 2017, 15, 5041-5054. [CrossRef] [PubMed]

16. Stoyanovsky, D.A.; Jiang, J.; Murphy, M.P.; Epperly, M.; Zhang, X.; Li, S.; Greenberger, J.; Kagan, V.; Bayır, H. Design and synthesis of a mitochondria-targeted mimic of glutathione peroxidase, MitoEbselen-2, as a radiation mitigator. ACS Med. Chem. Lett. 2014, 5, 1304-1307. [CrossRef] [PubMed]

17. Thanna, S.; Goins, C.M.; Knudson, S.E.; Slayden, R.A.; Ronning, D.R.; Sucheck, S.J. Thermal and photoinduced copper-promoted C-Se bond formation: Synthesis of 2-Alkyl-1,2-benzisoselenazol-3(2H)-ones and evaluation against mycobacterium tuberculosis. J. Org. Chem. 2017, 82, 3844-3854. [CrossRef] [PubMed]

18. Gordhan, H.M.; Patrick, S.L.; Swasy, M.I.; Hackler, A.L.; Anayee, M.; Golden, J.E.; Morris, J.C.; Whitehead, D.C. Evaluation of substituted ebselen derivatives as potential trypanocidal agents. Bioorg. Med. Chem. Lett. 2017, 27, 537-541. [CrossRef] [PubMed]

19. Singh, V.P.; Poon, J.; Yan, J.; Lu, X.; Ott, M.K.; Butcher, R.J.; Gates, P.J.; Engman, L. Nitro-, Azo-, and Amino derivatives of ebselen: Synthesis, structure, and cytoprotective effects. J. Org. Chem. 2017, 82, 313-321. [CrossRef] [PubMed]

20. Welter, A.; Leyck, S.; Etschenberg, E.; Nattermann, A.; Cie GmbH. Benzisoselenazolethiones and Process for the Treatment of Various Diseases in Humans. U.S. Patent 4711961, 8 December 1987.

21. Shakeel, A.; Altaf, A.A.; Qureshi, A.M.; Badashah, A. Thiourea Derivatives in Drug Design and Medicinal Chemistry: A Short Review. J. Drug Des. Med. Chem. 2016, 2, 10-20. [CrossRef]

22. Pacuła, A.J.; Kaczor, K.B.; Wójtowicz, A.; Antosiewicz, J.; Janecka, A.; Długosz, A.; Janecki, T.; Ścianowski, J. New glutathione peroxidase mimetics-Insights into antioxidant and cytotoxic activity. Bioorg. Med. Chem. 2017, 25, 126-131. [CrossRef] [PubMed] 
23. Ozturk, T.; Ertas, E.; Mert, O. Use of Lawesson's Reagent in Organic Syntheses. Chem. Rev. 2007, 107, 5210-5278. [CrossRef] [PubMed]

24. Pacuła, A.J.; Ścianowski, J.; Aleksandrzak, K.B. Highly efficient synthesis and antioxidant capacity of N-substituted benzisoselenazol-3(2H)-ones. RSC Adv. 2014, 4, 48959-48962. [CrossRef]

25. Pacuła, A.J.; Obieziurska, M.; Ścianowski, J.; Kaczor, K.B.; Antosiewicz, J. Synthesis of biologically active diaryl diselenides under water control. Arkivoc 2018, 3, 144-155.

26. Scheibye, S.; Kristensen, J.; Lawesson, S.O. Studies on organophosphorus compounds—XXVII1: Synthesis of thiono-, thiolo- and dithiolactones. Tetrahedron 1979, 35, 1339-1343. [CrossRef]

27. Kumakura, F.; Mishra, B.; Priyadarsini, K.I.; Iwaoka, M. A water-soluble cyclic selenide with enhanced glutathione peroxidase-like catalytic activities. Eur. J. Org. Chem. 2010, 440-444. [CrossRef]

28. Pacuła, A.J.; Kaczor, K.B.; Wójtowicz, A.; Antosiewicz, J.; Janecka, A.; Długosz, A.; Janecki, T.; Ścianowski, J. New chiral ebselen analogues with antioxidant and cytotoxic potential. Molecules 2017, 22, 492-506. [CrossRef] [PubMed]

29. Blum, J.; Fisher, A.; Greener, E. The catalytic decomposition of secondary carboxamides by transition-metal complexes. Tetrahedron 1973, 29, 1073-1081. [CrossRef]

30. Yao, B.; Wang, Q.; Zhu, J. Palladium(II)-catalyzed cyclizative cross-coupling of ortho-Alkynylanilines with ortho-Alkynylbenzamides under aerobic conditions. Angew. Chem. Int. Ed. 2013, 52, 12992-12996. [CrossRef] [PubMed]

31. Baldwin, R.M.; Lin, T.; Winchell, H.S.; Medi-Physics, Inc. Amides Useful as Brain Imaging Agents. U.S. Patent 4279887, 21 July 1981.

32. Pietka-Ottlik, M.; Wojtowicz-Młochowska, H.; Kolodziejczyk, K.; Piasecki, E.; Młochowski, J. New organoselenium compounds active against pathogenic bacteria, fungi and viruses. Chem. Pharm. Bull. 2008, 56, 1423-1427. [CrossRef] [PubMed]

33. Welter, A.; Lambert, C.; Dereu, N.; Huther, A.; Etschenberg, E.; Nattermann, A.; Cie GmbH. Benzisoselenazolonyl Derivatives and Processes for the Treatment of Rheumatic Disease. U.S. Patent 4774252, 27 September 1988.

(C) 2018 by the authors. Licensee MDPI, Basel, Switzerland. This article is an open access article distributed under the terms and conditions of the Creative Commons Attribution (CC BY) license (http:/ / creativecommons.org/licenses/by/4.0/). 